\title{
Conceptualizing the Effect of Cultural Distance on IT Outsourcing Success
}

\author{
Michael Könning \\ TU Dresden \\ Dresden, Germany \\ Email: michael.koenning@mailbox.tu-dresden.de
}

\begin{abstract}
The relationship quality between client and vendor organizations is one of the most significant influence factors for IT outsourcing success. In this context, the degree of dissimilarity between cultural values of two or more organizations ("cultural distance") can represent a considerable challenge for establishing and maintaining good-quality relationships. Still, research on cultural distance and its effects is scarce. This paper seeks to address this gap. Building on extant theory on culture and IT outsourcing, we develop a research model which we are currently evaluating. This is done by means of an exploratory, qualitative research design based on an in-depth single case study that analyzes three outsourcing configurations of a leading European media company. Their diversity allows for a detailed examination of cultural distance on the national, organizational, and team level. Given its highly relevant characteristics, we expect our research to yield valuable contributions for both theory and practice.
\end{abstract}

Keywords IT outsourcing, culture, cultural distance, relationship quality, ITO success, IT service types 


\section{Introduction}

Information technology outsourcing (ITO) has evolved into an essential strategic topic for organizations of all sectors and sizes ever since the first large-scale ITO engagement that involved the outsourcing of IT services from Eastman Kodak to four vendors in 1989 (Applegate 1992). 30 years later, its advantages in cost, flexibility, or access to external capabilities have made ITO a common practice to consider in organizations of all sizes, industries, and geographies, and led virtually every Fortune 500 company and many large public institutions to outsource significant parts of their IT ( Schneider and Sunyaev 2016).

Corresponding to ITO's increasing relevance in practice, academia has conducted extensive research on various aspects of outsourcing such as motivations for outsourcing, main decisions, outcomes and success factors, as well as benefits and risks (Dibbern et al. 2004; Gonzalez et al. 2006; Lacity et al. 2016; Liang et al. 2015). In terms of success factors, numerous studies have found the establishment of a highquality relationship between client and vendor organization to be highly influential for delivering successful ITO engagements (Gonzalez et al. 2015; Grover et al. 1996; Kern 1997; Kishore et al. 2003; Lee and Kim 1999; Murthy et al. 2016; Oshri et al. 2015). However, studies on how a positive relationship is established and maintained are still scarce (Jin Kim et al. 2013; Lacity et al. 2016; Xu and Yao 2014).

One of the most important and substantial, yet often overlooked influence factors in society and working relationships is culture. It exerts a subtle and unnoticed, yet powerful and oftentimes decisive influence on people, information flows, and the use and adaption of information systems (Leidner and Kayworth 2006). Previous studies have conceptualized culture in three levels (national, organizational, team) and analyzed the influence of a specific level on client-vendor relationship quality (Blaskovich and Mintchik 2011; Dibbern et al. 2012; Jain et al. 2011). However, by focusing on one or two levels, these studies paint an incomplete picture of cultural effects.

Furthermore, extant research has commonly investigated complete client-vendor partnerships as the smallest unit of analysis. However, these partnerships often comprise multiple individual services that are outsourced (e.g., application development and maintenance, infrastructure operations, IT support). Second, considerable cultural distance can be mitigated by appropriate leadership that is culturally aware and intelligent, e.g., when leaders are able to identify and interpret culture-induced statements or actions, take on a moderating role and thereby alleviate negative effects of cultural distance (Winkler et al. 2008). Hence, in summary, our research seeks to answer the following three research questions:

RQ1: How does cultural distance on the national, organizational, and team level influence clientvendor relationship quality and ITO success?

RQ2: How does the outsourced IT service type moderate the effect of cultural distance?

RQ3: To which degree can cultural awareness and intelligence mitigate the effect of cultural distance?

The remainder of this paper is structured as follows: The next section provides a brief introduction into related work in ITO, client-vendor relationship quality, and culture. Based on these fundamentals, we then develop our research model before describing research method and case setting. Lastly, section 5 gives an overview of our preliminary findings and outlines expected contributions to theory and practice. For brevity, we center this article around the derivation and development of our research model, and refer to our future contributions for further empirical analyses.

\section{Theoretical Background and Related Work}

\subsection{IT Outsourcing}

ITO can be defined as "the commissioning of a third party (or a number of third parties) to manage a client organization's IT assets, people, and/or activities (or part of them) to required results" (Dibbern et al. 2004). It can take on many different forms along several dimensions, be it the scope of IT services to be outsourced (partial or full outsourcing), the number of vendors to partner with (single-vendor sourcing vs. multi-vendor sourcing), or the location of service fulfillment (onshoring, offshoring, nearshoring). The consequential plurality of possible sourcing configurations is mirrored by a myriad of academic studies on the topic (Dibbern et al. 2004; Gonzalez et al. 2006; Lacity et al. 2016).

However, across all these dimensions, ITO always involves the partnering of two or more organizations over the provision of one or more IT services. The concept of such a relationship is closely linked to Social Exchange Theory which explicitly examines the social processes between multiple parties (Homans 1958). Accordingly, the establishment and management of a strong client-vendor relationship is one of the strongest predictors for success in ITO engagements (Grover et al. 1996; Lee and Kim 1999). 
The value of a high-quality client-vendor relationship is particularly true for long-term ITO engagements with a broad scope of service provision. In this setting, contracts are typically unable to adequately predict and meet the dynamics of the business environment (Jin Kim et al. 2013). Academic research has therefore devoted considerable resources to understand the influence factors for the quality of clientvendor relationships (Kern 1997; Kishore et al. 2003). Among their most significant is culture.

\subsection{The Concept and Influence of Culture}

The concept of culture is complex and multi-faceted in nature. One of the first and arguably most influential definitions of culture was established by Tylor (1889) who described culture as "that complex whole which includes knowledge, belief, art, morals, law, customs and any other capabilities and habits acquired by man as a member of society" (p. 1). Another popular definition is provided by Hofstede et al. (2010) who see culture as "the collective programming of the mind that distinguishes the members of one group or category of people from another" (p. 6).

Based on this definition, the term 'cultural distance' can be used to express the degree of dissimilarity between cultural values of two or more organizations. Cultural distance becomes observable in differing beliefs about what values, behaviors, goals, or policies are considered important or unimportant, appropriate or inappropriate, and right or wrong.

Because of its complexity and the difficulty to grasp it in its entirety, it has been proposed to disintegrate culture into its constituent parts and analyze it in a structured manner. Following the work by Leidner and Kayworth (2006), we therefore conceptualize culture in three layers: national, organizational, and team culture.

\subsubsection{National Culture}

Differences in national culture are part of every nearshore and offshore outsourcing engagement. A very popular breakdown of national culture is offered by Hofstede et al. (2010) who originally described it as differences in four dimensions (Hofstede 1983), then later added two additional dimensions (Hofstede et al. 2010). Many studies on ITO relationship quality have itemized and used them as a means to assess and compare national cultures (Leidner and Kayworth 2006). They are defined in the following.

Individualism vs. collectivism: The degree to which members of a society act as individuals rather than as members of a group (Hofstede et al. 2010). Extant literature finds that individualists and collectivists perform differently in different group settings. While collectivists were found to work better as part of a group, individualistic people performed better when working alone (Earley 1993).

Masculinity vs. femininity: Describes whether a society is called masculine, i.e. when emotional gender roles are clearly distinct in that "men are supposed to be assertive, tough and focused on material success, whereas women are supposed to be more modest, tender, and concerned with the quality of life" (Hofstede et al. 2010, p. 140). It is called feminine when emotional gender roles overlap.

Power distance: "The extent to which the less powerful members of [...] organizations within a country expect and accept that power is distributed unequally" (Hofstede et al. 2010, p. 61). It ranges from relatively low (i.e., equal distribution of power, e.g., in Germany) to relatively high (unequal distribution of power, e.g., in India). Extant ITO literature finds that different degrees of power distance lead to problems in communication and decision-making (Heeks et al. 2001; Nicholson and Sahay 2001).

Uncertainty avoidance: "The extent to which the members of a culture feel threatened by ambiguous or unknown situations" (Hofstede et al. 2010, p. 191). Cultures that are high in uncertainty avoidance are considered to be more resistant to change.

Long-term vs. short-term orientation: Hofstede's fifth dimension distinguishes between long-term orientation, the emphasis on virtues that are oriented toward future rewards (e.g., perseverance and thrift), and short-term orientation, i.e., the emphasis on virtues oriented towards present and past (e.g., respect for tradition, preservation of face, fulfilling social obligations) (Hofstede et al. 2010).

Indulgence vs. restraint: Indulgence is conceptualized as "tendency to allow relatively free gratification of basic and natural human desires related to enjoying life and having fun" (ibid. p. 281). The opposite form is restraint, i.e. the "conviction that such gratification needs to be curbed and regulated" (p. 281).

Extant literature has also identified influential differences on three additional dimensions:

Activity vs. passivity: A society is considered active if members see themselves as doers (actively contribute own ideas to shape their environment), and passive if members consider themselves as reactors to the world (Lytle et al. 1995). 
Language and communication style: Refers to any differences, difficulties and misunderstandings due to the use of the common language used in the interaction (Carmel and Agarwal 2002). A second part is the way that a given language is used, i.e. the communication style which can be more abstractive or assertive, high context or low context, more holistic or more linear. Lytle et al. (1995) find that different communication styles are more likely to lead to misunderstandings and conflict.

Conflict resolution: Describes the way that a culture typically handles and solves conflict situations. Koh et al. (2009) illustrates how members from low power distance and more individualistic cultures voice disagreements by means of direct confrontation, whereas members of collectivistic and high power distance cultures tend to avoid and withdraw from conflict situations.

\subsubsection{Organizational Culture}

Analogous to how each ethnical group, society or nation is characterized by their specific national culture, each organization within a society develops its own organizational culture. It can be defined as "the pattern of shared values and beliefs that help individuals understand organizational functioning and provide norms for behavior in the organizations" (Deshpande and Webster 1989). I again draw on Hofstede et al. (2010) who isolated six work-related dimensions as characteristics of an organization:

Process-oriented vs. result-oriented: This dimension contrasts a culture with strict adherence to predefined, risk-minimized, routine-based processes (process-oriented) with one where goals are the core concern, with less focus on how they are achieved (results-oriented). In practice, process-oriented organizations tend to be more rigid, result-oriented work teams are more flexible and organic.

Employee-oriented vs. job-oriented: This dimension opposes an orientation towards people (employeeoriented) to an orientation on completing the work (job-oriented). While employee-oriented cultures take a responsibility for employee welfare and respect employees' private life, employees in job-oriented cultures perceive the organization as only interested in the work they fulfilled, not their private welfare.

Parochial vs. professional: This dimension discerns between organizations whose employees strongly connect their identity and private life with the organization and feel hired as a whole person (parochial) from those where people consider their private life and identity their own business and feel the organization solely hires on the basis of job competence (professional).

Open system vs. closed system: This dimension depicts whether members of an organization consider it open to outsiders and newcomers, where new members feel at home after a short period of time (open system), or whether they perceive it to be closed and secretive, even to society members (closed system).

Loose control vs. tight control: This dimension measures the amount of internal structuring of an organization. Employees in loose control organizations typically report that meeting times are only kept approximately and cost awareness is rather low. In contrast, work in organizations with tight control is carried out more cost-conscious and meeting times tend to be kept more diligently.

Normative vs. pragmatic: Hofstede's sixth dimension evaluates organizations in terms of customer orientation. It locates organizations between normative units where the main emphasis is on strictly adhering to organizational procedures, whereas pragmatic units are described as market-driven with strong focus on customer needs. In these units, results are more important than correct procedures.

\subsubsection{Team Culture}

Like every organization is influenced by the superordinate national culture, each team is subject to the superordinate organizational culture. As a result, different teams within the same organization partly exhibit the same values, and partly differ from each other. Culture on the team level is also strongly influenced by team or project leaders, e.g., their task assignment and scheduling of deadlines (Guinan et al. 1998). Consequentially, extant literature finds that similar values on work mode and task accomplishment lead to less conflict and more successful project outcomes (Walsham and Geoff 2002).

\subsection{ITO Success and Relationship Quality}

Since our research investigates the effect of cultural distance on ITO success, it is important to define what constitutes ITO success and how it is influenced. Extant literature suggests that the main reasons for ITO include access to expertise/skills, cost reductions, flexibility enablement, and service quality (Lacity et al. 2016). The better these goals are met, the higher the client satisfaction (Grover et al. 1996; Lee and Kim 1999). Our study will therefore use these four reasons as indicator to measure ITO success.

In various empirical studies, the relationship quality between client and vendor organization has been found to have a strong influence on ITO success (Dibbern et al. 2004; Grover et al. 1996; Lee and Kim 
1999; Westner and Strahringer 2010). In line with Winkler et al. (2008), it can be defined as "the degree of connectedness between a client and a vendor in the aim to achieve specified goals" (p. 245). Extant research has identified several attributes that determine the quality of an ITO relationship. Among them are communication, cooperation, trust and vendor performance which positively affect relationship quality, and conflict which exerts a negative effect (Dibbern et al. 2004; Lacity et al. 2016).

\section{Research Model}

For our research model we integrate the concept of cultural distance on the national, organizational, and team level. Building on the work of Winkler et al. (2008), we argue that cultural distance on each of these levels leads to behavioral differences in service delivery (i.e., work in the context of an ITO engagement) which, in turn, reduce relationship quality by hampering communication, cooperation, trust, and vendor performance, and lead to increased levels of conflict. Reductions in relationship quality then lead to reduced ITO success.

In addition, the relationship between behavioral differences in service delivery and relationship quality is moderated by two factors: Interaction necessity describes the amount of interaction between client and vendor that is required in delivering the contracted service. We argue that it depends on the specific service type that is outsourced and is higher for application development and maintenance than for infrastructure operations. Second, leadership and management of culture has been found to reduce negative effects of cultural distance on relationship quality. It requires cultural awareness and intelligence (Winkler et al. 2008). The resulting research model is shown in Figure 1.

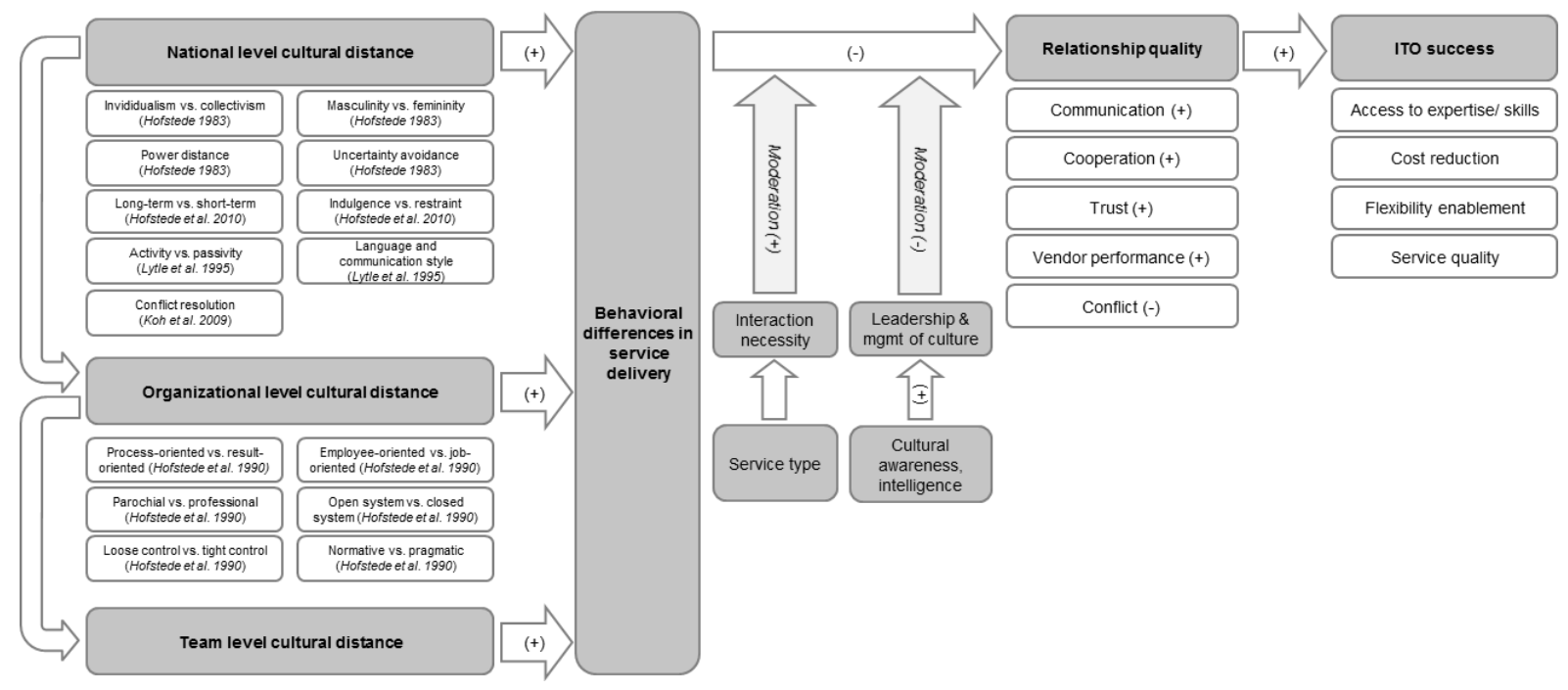

Figure 1: Research model

\section{Research Design and Case Description}

Our research follows an exploratory, qualitative research design based on an in-depth single case study. The case study method was chosen because it has been described as especially applicable for exploratory research and theory building (Eisenhardt 1989). The case study used for this research is that of a leading European media company. Between 2008 and 2018, the organization went through three phases of ITO: (1) An initial single-vendor full outsourcing and offshoring to a large multi-national vendor with service delivery from India, (2) a single-vendor outsourcing with the same partner in a mixed offshore/onshore delivery model, and (3) a multi-vendor model with two local mid-sized vendors onshore, accompanied by an increased share of insourcing. This makes the case highly relevant for evaluating the research model because its three ITO phases represent three different configurations of cultural distance.

During the first phase, client and vendor organization were separated by different national as well as organizational cultures. In the second phase, services were partly provided from onshore, thus reducing national level cultural distance, while keeping organizational distance. Finally, in the third phase, the client company shifted to a multi-vendor configuration with different onshore vendors and an increased share of insourcing. In addition to eliminating national level cultural distance through onshoring, the client company minimized organizational and team level cultural distance by considering cultural compatibility as part of their vendor selection process. For the insourced services, national level and organizational level distance are nonexistent, which allows a clear view on team level cultural distance. 
Due to its unique setup and three culturally different configurations, this case study promises valuable insights into the effect of all three levels of cultural distance on ITO success. Moreover, by concentrating on a single case study, we inherently control for other variables that influence relationship quality and ITO success, especially all client characteristics and capabilities, as well as certain project characteristics.

This research project is and will be conducted as follows: After deriving a research model from extant literature and identifying a relevant case, we evaluated relevant documents in the case company (e.g., status reports, steering committee documents) and interviewed key staff involved with the ITO decisions over the last ten years, including the company's CIO, responsible project managers, and ITO strategists. This allowed us to get a first understanding of the situation and identify additional key informants. Next, we will use the research model presented here to derive a semi-structured interview guideline that will include questions on cultural distance, relationship quality, ITO success, and potential moderators. The interview guideline will then be used to conduct additional interviews with key staff from both the client and vendor organizations to obtain deeper insights into particularly relevant parts of the case. In the third phase, we will transcribe and qualitatively analyze the interviews along the research model.

\section{Preliminary Findings and Expected Contribution}

After the first set of interviews and document analyses, our preliminary findings point towards a strong influence of cultural distance on relationship quality and ITO success, especially on the national and organizational level. Talking about the first phase of ITO (single-vendor offshoring), managers in the client organization particularly stressed how differences in communication style, conflict resolution, and activity/passivity inhibited the establishment of trust and effective cooperation schemes. Consequently, these differences in national culture led to the shift towards a combined offshore/onshore model in the second phase. As a result, cultural distance on the national level was greatly reduced, but organizational level differences persisted and showed in daily procedures. As their CIO put it:

"We are not a company that is very compatible with someone like [ITO vendor]. They are very processfocused, very professional, somewhat formal, if you will. Our organization, on the other hand, is quite the opposite: Rather informal, very pragmatic, very agile - and that just doesn't go together very well!"

The company said they tried to address these issues by implementing adequate management practices. However, significantly improving the situation required another strategy shift towards two smaller ITO vendors that currently provide the services from onshore. In this model, cultural distance is nonexistent on the national level and greatly reduced on the organizational level. During the first interviews, client company representatives said that the organization has learned from these ITO reconfigurations in that cultural distance now plays a decisive role in their vendor selection process. Today, partnerships with more reasonable cultural distance are preferred, even if they come with an added expense.

Based on our first results, we expect valuable contributions for both research and practice. For academia, this case study can provide additional empirical evidence on how cultural distance influences outsourcing success. By providing a multi-level perspective on culture that is also reflected in the case setup, it promises to contribute to the existing research body on the effect of culture on ITO. On the practical side, the case study can serve as a highly relevant insight into the ITO practices of a leading European media company, explain how cultural effects influence ITO, and provide information on how and which methods can help in mitigating the effect. Last, it will also explain what lessons can be learned from cultural misfit and how it is avoided using adequate ITO vendor selection processes.

\section{References}

Applegate, L. M. 1992. “Eastman Kodak Co.: Managing Information Systems Through Strategic Alliances: Harvard Business School Teaching Note 193-037," Harvard Business School, Boston, MA, USA.

Blaskovich, J., and Mintchik, N. 2011. "Information Technology Outsourcing: A Taxonomy of Prior Studies and Directions for Future Research,” Journal of Information Systems (25:1), pp. 1-36.

Carmel, E., and Agarwal, R. 2002. "The Maturation of Offshore Sourcing of Information Technology Work," MIS Quarterly Executive (1:2), pp. 65-77.

Deshpande, R., and Webster, F. E. 1989. "Organizational Culture and Marketing: Defining the Research Agenda," Journal of Marketing (53:1), pp. 3-15.

Dibbern, J., Chin, W. W., and Heinzl, A. 2012. "Systemic Determinants of the Information Systems Outsourcing Decision: A Comparative Study of German and United States Firms," Journal of the Association for Information Systems (13:6), pp. 466-497.

Dibbern, J., Goles, T., Hirschheim, R., Bandula, J., and Jayatilaka, B. 2004. "Information Systems Outsourcing," The DATA BASE for Advances in Information Systems (35:4), pp. 6-102. 
Earley, P. C. 1993. "East Meets West Meets Mideast: Further Explorations of Collectivistic and Individualistic Work Groups," Academy of Management Journal (36:2), pp. 319-348.

Eisenhardt, K. M. 1989. "Building Theories from Case Study Research," Academy of Management Review (14:4), pp. 532-550.

Gonzalez, R., Gasco, J., and Llopis, J. 2006. "Information Systems Outsourcing: A Literature Analysis," Information \& Management (43:7), pp. 821-834.

Gonzalez, R., Gasco, J. L., and Llopis, J. 2015. "Information Systems Outsourcing Satisfaction: Some Explanatory Factors," Industrial Management \& Data Systems (115:6), pp. 1067-1085.

Grover, V., Cheon, M. J., and Teng, J. T.C. 1996. "The Effect of Service Quality and Partnership on the Outsourcing of Information Systems Functions," Journal of Management Information Systems (12:4).

Guinan, P. J., Cooprider, J. G., and Faraj, S. 1998. "Enabling Software Development Team Performance During Requirements Definition," Information Systems Research (9:2), pp. 101-125.

Heeks, R., Krishna, S., Nicholson, B., and Sahay, S. 2001. "Synching or Sinking: Global Software Outsourcing Relationships," IEEE Software (March/April 2001), pp. 54-60.

Hofstede, G. 1983. "National Cultures in Four Dimensions: A Research-Based Theory of Cultural Differences among Nations," International Studies of Management \& Organization (13:1), pp. 46-74.

Hofstede, G., Hofstede, G. J., and Minkov, M. 2010. Cultures and Organizations: Software of the Mind. Intercultural Cooperation and its Importance for Survival, New York: McGraw-Hill.

Homans, G. C. 1958. “Social Behavior as Exchange,” American Journal of Sociology (63:6), pp. 597-606.

Jain, R. P., Simon, J. C., and Poston, R. S. 2011. "Mitigating Vendor Silence in Offshore Outsourcing: An Empirical Investigation," Journal of Management Information Systems (27:4), pp. 261-298.

Jin Kim, H., Shin, B., and Lee, H. 2013. "The Mediating Role of Psychological Contract Breach in IS Outsourcing," European Journal of Information Systems (22:5), pp. 529-547.

Kern, T. 1997. "The Gestalt of an Information Technology Outsourcing Relationship: An Exploratory Analysis," Proceedings of the 18th International Conference on Information Systems, pp. 37-58.

Kishore, R., Rao, H. R., Nam, K., Rajagopalan, S., and Chaudhury, A. 2003. "A Relationship Perspective on IT Outsourcing," Communications of the ACM (46:12), pp. 86-92.

Koh, C., Joseph, D., and Ang, S. 2009. "Cultural Intelligence and Collaborative Work: Intercultural Competencies in Global Technology Work Teams," International Workshop on Intercultural Collaboration, pp. 261-264.

Lacity, M. C., Khan, S. A., and Yan, A. 2016. "Review of the Empirical Business Services Sourcing Literature: An Update and Future Directions," Journal of Information Technology (31:3), pp. 269-328.

Lee, J.-N., and Kim, Y.-G. 1999. "Effect of Partnership Quality on IS Outsourcing Success: Conceptual Framework and Empirical Validation,” Journal of Management Information Systems (15:4), pp. 29-61.

Leidner, D., and Kayworth, T. 2006. "A Review of Culture in Information Systems Research: Toward a Theory of Information Technology Culture Conflict," MIS Quarterly (30:2), pp. 357-399.

Liang, H., Wang, J.-j., Xue, Y., and Cui, X. 2015. "Information \& Management IT Outsourcing Research from 1992 to 2013: A Literature Review Based on Main Path Analysis," Information \& Management.

Lytle, A. L., Brett, J. M., Barsness, Z., and Janssens, M. 1995. "A Paradigm for Confirmatory Cross-Cultural Research in Organizational Behavior," Research in Organizational Behavior (17), pp. 167-214.

Murthy, C., Padhi, S., Gupta, N., and Kapil, K. 2016. "An Empirical Investigation of the Antecedents of Value CoCreation in B2B IT Services Outsourcing," Business Process Management Journal (22:3), pp. 484-506.

Nicholson, B., and Sahay, S. 2001. "Some Political and Cultural Issues in the Globalisation of Software Development: Case Experience from Britain and India," Information and Organization (11), pp. 25-43.

Oshri, I., Kotlarsky, J., and Gerbasi, A. 2015. "Strategic Innovation Through Outsourcing: The Role of Relational and Contractual Governance," Journal of Strategic Information Systems (24:3), pp. 203-216.

Schneider, S., and Sunyaev, A. 2016. "Determinant Factors of Cloud-Sourcing Decisions: Reflecting on the IT Outsourcing Literature in the Era of Cloud Computing," Journal of Information Technology (31:1), pp. 1-31.

Tylor, E. B. 1889. Primitive Culture: Researches into the Development of Mythology, Philosophy, Religion, Language, Art, and Custom: Holt.

Walsham, and Geoff. 2002. "Cross-Cultural Software Production and Use: A Structurational Analysis," MIS Quarterly (26:4), pp. 359-380.

Westner, M., and Strahringer, S. 2010. "Determinants of Success in IS Offshoring Projects: Results from an Empirical Study of German Companies," Information \& Management (47:5-6), pp. 291-299.

Winkler, J. K., Dibbern, J., and Heinzl, A. 2008. "The Impact of Cultural Differences in Offshore Outsourcing: Case Study Results from German-Indian Application Development Projects," Information Systems Frontiers (10:2), pp. 243-258.

Xu, P., and Yao, Y. 2014. "Knowledge Sharing in Offshore Software Development: A Vendor Perspective," Journal of Global Information Technology Management (16:1), pp. 58-84. 
Copyright: (C) 2018 Michael Könning. This is an open-access article distributed under the terms of the Creative Commons Attribution-NonCommercial 3.0 Australia License, which permits non-commercial use, distribution, and reproduction in any medium, provided the original author and ACIS are credited. 